\title{
An Uncommon Localization of a Hydatid Cyst Presenting with Pulmonary Embolism
}

\author{
Francesco Finizola ${ }^{1 *}$, Giovanni Donati ${ }^{1}$, Javier Rosada ${ }^{2}$, Irene Carlotta Bogazzi ${ }^{1}$ and Pier Leopoldo Capecchi ${ }^{1}$ \\ ${ }^{1}$ Department of Medical Sciences, Surgery and Neurosciences, University of Siena, Italy \\ ${ }^{2}$ Department of Internal Medicine, University of Pisa, Italy
}

Submission: October 21, 2021; Published: November 23, 2021

*Corresponding author: Francesco Finizola, Department of Medical Sciences, Surgery and Neurosciences, Department of Medical Biotechnologies, University of Siena, Siena, Italy

Abstract

Human echinococcosis is an important infection in undeveloped and developing countries, caused by larval forms of the genus Echinococcus. In western countries this disease is sporadic. The organs mostly involved by the cysts are the liver (70\%) and the lungs (20\%) [1]. Cardiac hydatid cyst is a rare condition, and the location of a hydatid cyst in the interventricular septum is exceptional. Cardiac echinococcosis is not frequent, only $0.01 \%-2 \%$ of all hydatid infestations [2]. The left ventricle is the heart chamber most frequently involved (55-60\%) and the involvement of the interventricular septum is reported in $4 \%$ of cardiac cases. Chest pain, palpitations, and dyspnea are the most frequent symptoms associated with cardiac echinococcosis. We describe a case of an unusual presentation of this disease.

Keywords: Echocardiography; Interventricular septum; Hydatid cyst; Echinococcosis

\section{Case Report}

A 39-year-old Caucasian female was admitted to our department for the evaluation of syncope and dyspnea. Two years before, the patient presented with an abdominal pain. An abdominal echography revealed the presence of two liver hydatic cyst. Treatment with Albendazole was undertaken for one year with improvement of symptoms. Physical and neurological examination revealed nothing unusual and routine laboratory tests were normal. Chest CT scan showed pulmonary embolism involving principal arteries and a mass in the right ventricle, initially interpreted as a tumor or blood clot. A transthoracic echocardiography was done and revealed the presence of a $40 \times 25 \mathrm{~mm}$ cystic mass in the apical part of interventricular septum with protrusion to the right ventricle cavity. ELISA test was positive for echinococcosis antibodies. Albendazole was started for 6 months with an improvement of pulmonary symptoms. Then, cystectomy was performed and the remaining cyst contents and germinative membrane were removed. Histopathological exam of cystic material confirmed the diagnosis of hydatid cyst. The postoperative period was uneventful, and the patient was discharged from the hospital.

\section{Discussion}

Echinococcosis or hydatid disease is caused by larval stage of Echinococcus granulosus. Humans are only intermediate and accidental hosts. ELISA is the most specific serologic tests that can be used and a positive result for echinococcus antibodies confirms the diagnosis. Cardiac hydatidosis is a rare condition potentially fatal or leading to severe complications without treatment being undertaken. The most common cardiac locations are left ventricular wall (60\%), right ventricle (10\%), pericardium (7\%), left atrium (6-8\%), right atrium (4\%), and the interventricular septum (4\%). Right ventricle is rarely involved and cysts are more prone to rupture, as compared to cysts on the left ventricle. This condition may lead to pulmonary embolization, a lethal complication. Such a condition should be taken into consideration as other complications (arrhythmia, angina, dysfunction of valvular and ventricular functions) may initially give the same symptoms. Echocardiography is the most efficient method in the diagnosis of cardiac hydatid cyst [3]. CT scan and MRI can be used to detect the involvement of other organs, but they have a low sensitivity and 


\section{Juniper Online Journal of Case Studies}

a low sensitivity in the diagnosis of intra-ventricular hydatidosis. Transesophageal ecography can provide a more accurate definition of the mass. Surgical excision with removing germinal layer and albendazole therapy showed successful results in treating cardiac hydatid cysts [4] (Figure A-C).

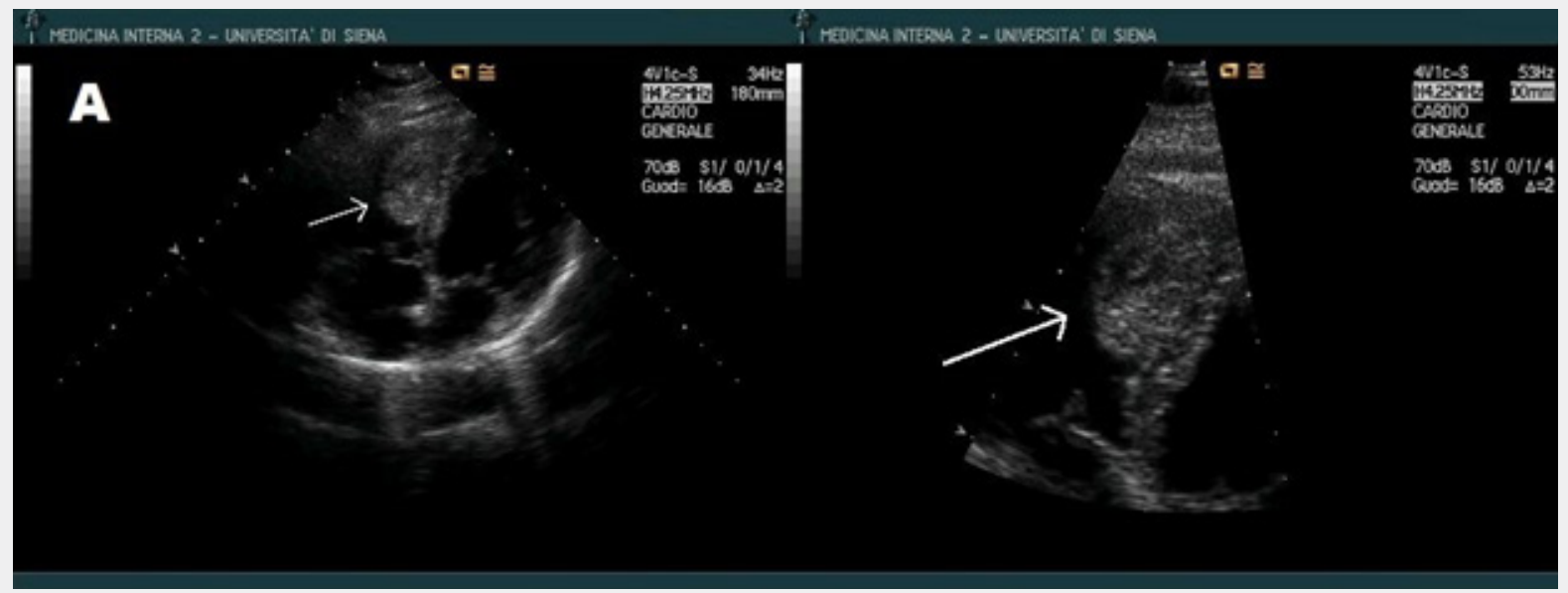

Figure A: Transthoracic echocardiogram revealed a large $4 \mathrm{~cm} \times 2.5 \mathrm{~cm}$ cystic lesion mass in the apical part of interventricular septum with protrusion to right ventricle cavity.

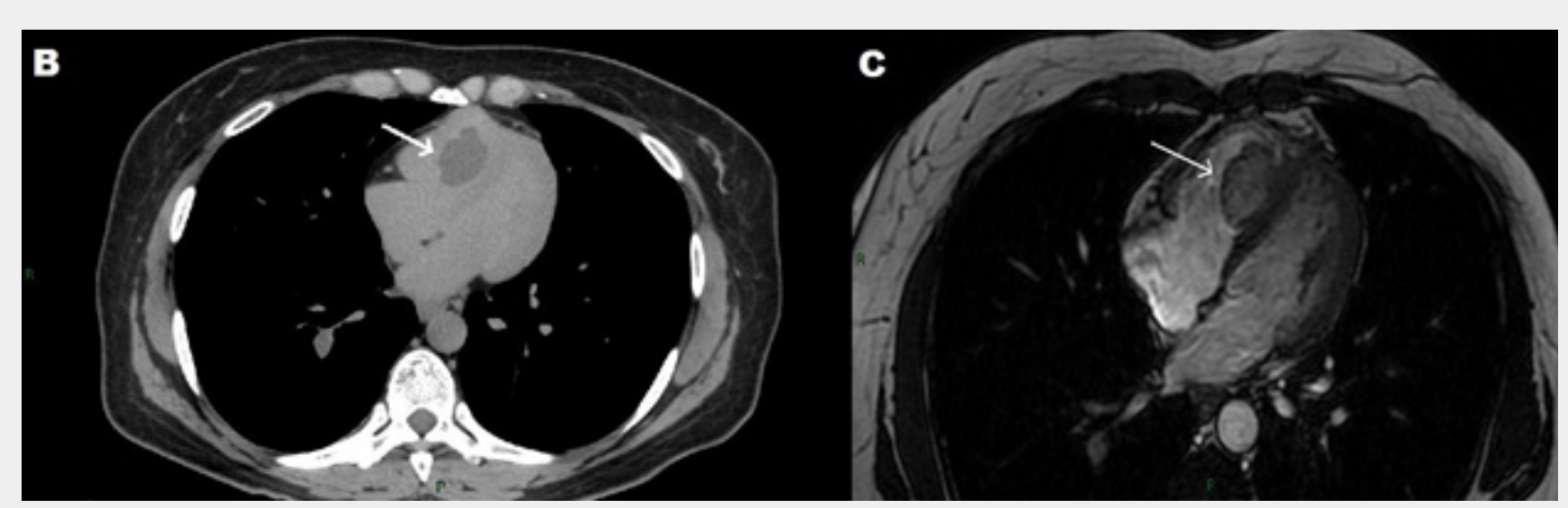

Figure B \& C: CT-scan and MRI images of cystic lesion in right ventricle cavity.

\section{References}

1. Eckert J, Gemmell MA, Meslin FX, Pawlowski ZS (2001) WHO-OIE Manual on Echinococcosis in Humans and Animals: A Public Health Problem of Global Concern. Paris: World Organisation for Animal Health.

2. Maffeis GR, Petrucci O, Carandina R, Leme CA Jr, Truffa M, et al. (2000) Cardiac echinococcosis. Circulation 101(11): 1352-1354.
3. Oliver JM, Sotillo JF, Domínguez FJ, López de Sá E, Calvo L, et al. (1988) Two dimensional echocardiography feutures of echinococcosis of the heart and great blood vessel, clinical and surgical implications. Circulation 78: 327-337.

4. Yan F, Huo Q Abudureheman M, Qiao J, Ma S, etal.(2015) Surgical treatment and outcome of cardiac cystic echinococcosis. Eur J Cardiothorac Surg 47(6): 1053-1058 
(C) This work is licensed under Creative

(C) DOI: 10.19080/JOJCS.2021.12.555847
Your next submission with Juniper Publishers will reach you the below assets

- Quality Editorial service

- Swift Peer Review

- Reprints availability

- E-prints Service

- Manuscript Podcast for convenient understanding

- Global attainment for your research

- Manuscript accessibility in different formats

( Pdf, E-pub, Full Text, Audio)

- Unceasing customer service

Track the below URL for one-step submission https://juniperpublishers.com/online-submission.php 